\title{
Levosimendan is superior to epinephrine in improving myocardial function after cardiopulmonary bypass with deep hypothermic circulatory arrest in rats
}

\author{
Alessio Rungatscher, MD, PhD, Daniele Linardi, MD, Maddalena Tessari, MSc, Tiziano Menon, MSc, \\ Giovanni Battista Luciani, MD, Alessandro Mazzucco, MD, and Giuseppe Faggian, MD
}

\begin{abstract}
Objective: To investigate effects of epinephrine and levosimendan on cardiac function after rewarming from deep hypothermia.

Methods: Forty-five male Wistar rats (400-500 g) underwent cardiopulmonary bypass and were cooled to a core temperature of $13^{\circ} \mathrm{C}$ to $15^{\circ} \mathrm{C}$ within 30 minutes. After 15 minutes of deep hypothermic circulatory arrest, they were randomly assigned to treatment with levosimendan $\left(12 \mu \mathrm{g} / \mathrm{kg}\right.$; infusion of $\left.0.2 \mu \mathrm{g} \cdot \mathrm{kg}^{-1} \cdot \mathrm{min}^{-1}\right)(\mathrm{n}=15)$ or epinephrine $\left(0.1 \mu \mathrm{g} / \mathrm{kg}\right.$; infusion of $\left.0.1 \mu \mathrm{g} \cdot \mathrm{kg}^{-1} \cdot \mathrm{min}^{-1}\right)(\mathrm{n}=15)$ or saline as control $(\mathrm{n}=10)$. The rewarming lasted 60 minutes. Systolic and diastolic function was evaluated at different preloads with a conductance catheter, including the slope of the end-systolic pressure-volume relation (ESPVR) and end-diastolic pressure-volume relationship (EDPVR), preload recruitable stroke work, first derivative of left ventricular pressure $(+\mathrm{dP} / \mathrm{dt})$, and its relation to end-diastolic volume, as well as the time constant of left ventricular relaxation (Tau) and maximal slope of the diastolic pressure decrement ( $-\mathrm{dP} / \mathrm{dt})$. Plasma lactate levels were collected.
\end{abstract}

Results: Stroke volume, ejection fraction and $+\mathrm{dP} / \mathrm{dt}$ were significantly higher in the levosimendan-treated group than in the epinephrine group. The slope values of preload recruitable stroke work, ESPVR, and the relation of $+\mathrm{dP} / \mathrm{dt}$ to end-diastolic volume were significantly higher, indicating a better contractility and increased systolic function. $-\mathrm{dP} / \mathrm{dt}$ was significantly higher in the levosimendan group (3468 \pm 320 vs $1103 \pm$ $101 \mathrm{~mm} \mathrm{Hg} / \mathrm{s} ; P<.01$ ). Left ventricular stiffness expressed by EDPVR and relaxation (Tau) were significantly improved in levosimendan-treated group. Plasma lactated concentrations were lower in levosimendan group $(2.03 \pm 1.27$ vs $4.64 \pm 1.02 ; P<.05)$.

Conclusions: Levosimendan has better inotropic and lusitropic effects than epinephrine during rewarming from deep hypothermic circulatory arrest with cardiopulmonary bypass. (J Thorac Cardiovasc Surg 2012;143:209-14)

Deep hypothermic circulatory arrest (DHCA) is widely used during repair of the aortic arch and congenital heart defects as a method of cerebral protection. Since the 1980s, when DHCA became widely used, surgical outcome has improved along with survival and cardiac morbidity. ${ }^{1}$ Nevertheless, the effect of myocardial ischemia-reperfusion injury combined with hypothermia-rewarming has important clinical implications and remains a significant contributor to perioperative morbidity and mortality. ${ }^{2}$

Similar to the cardiac surgical setting, hypotension and low cardiac output are common after rewarming from accidental hypothermia, and up to $50 \%$ to $80 \%$ of patients have

From the Department of Surgery, Division of Cardiac Surgery, University of Verona, Verona, Italy.

Disclosures: Authors have nothing to disclose with regard to commercial support.

Read at the 91st Annual Meeting of The American Association for Thoracic Surgery, Philadelphia, Pennsylvania, May 7-11, 2011.

Received for publication May 10, 2011; revisions received Aug 18, 2011; accepted for publication Sept 15, 2011; available ahead of print Oct 19, 2011.

Address for reprints: Alessio Rungatscher, MD, PhD, Department of Surgery, University of Verona, Piazzale Stefani 1, 37126 Verona, Italy (E-mail: alessio. rungatscher@univr.it).

$0022-5223 / \$ 36.00$

Copyright (c) 2012 by The American Association for Thoracic Surgery

doi:10.1016/j.jtcvs.2011.09.020 hemodynamic instability. ${ }^{3}$ Underlying this process, there is an overall myocardial depression, including both systolic and diastolic dysfunction, that may require the use of inotropic drugs. ${ }^{4}$

Clinical guidelines for management of myocardial dysfunction, either in the setting of cardiac surgical interventions or in accidental hypothermia, are still undetermined. Epinephrine is currently used in the treatment of hypothermia-induced cardiac dysfunction. ${ }^{5}$ However, the evidence of efficacy of epinephrine in this setting has been questioned. ${ }^{4,6,7}$

This study was designed to investigate whether levosimendan, a $\mathrm{Ca}^{2+}$ sensitizer, may be effective in improving myocardial dysfunction after rewarming from DHCA and to compare its efficacy with that of epinephrine.

\section{METHODS}

\section{Rat Cardiopulmonary Bypass (CPB) Model}

After institutional animal care committee approval, 45 male Wistar rats (400-450 g; Harlan, Udine, Italy) housed under standard laboratory conditions were anesthetized (sodium penthobarbital, $30 \mathrm{mg} / \mathrm{kg}$ intraperitonally) and intubated through the oropharynx with a 14-gauge polyethylene tube. They were mechanically ventilated with a rodent respirator (Harvard Apparatus Inc, Holliston, Mass). The tidal volume was $7 \mathrm{~mL} / \mathrm{kg}$ and the 


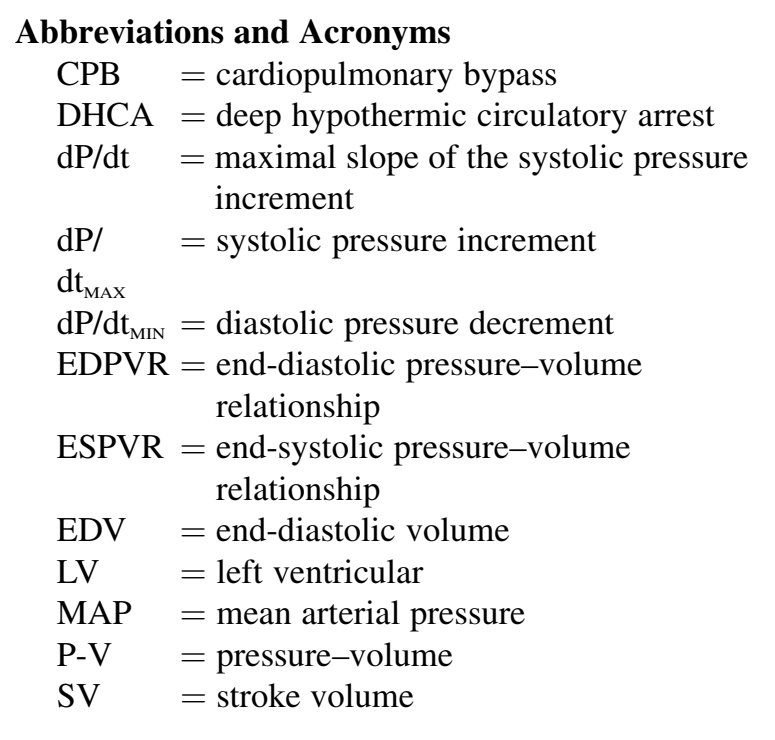

respiratory rate was 50 to 60 breaths/min with an air-oxygen mixture (inspired oxygen fraction $=0.5$ ). Ventilation was adjusted to keep an arterial carbon dioxide tension of 35 to $45 \mathrm{~mm} \mathrm{Hg}$. Rats were secured supine on a heating board to maintain rectal temperature at $37^{\circ} \mathrm{C}$ during the surgical procedure before the initiation of $\mathrm{CPB}$. A thermocouple microprobe was inserted into the left femoral artery and advanced into the descending aorta for the measurement of blood temperature. The left femoral artery was cannulated with a heparinized 24-gauge Teflon catheter to monitor systemic arterial pressure and to collect arterial blood for gas analysis. Central cannulation was performed as previously described. ${ }^{8}$ In brief, after complete sternotomy, a venous cannula (a modified 4-hole 16-gauge Angiocath catheter) was advanced into the right atrium using a right trans-superior vena cava approach, allowing excellent drainage. The left common carotid artery was cannulated using an 18-gauge catheter advanced to the aortic arch and connected to the arterial perfusion line for the CPB circuit. Full heparinization $(500 \mathrm{IU} / \mathrm{kg}$ ) was assured after surgical preparation and immediately before CPB initiation to reduce overall blood loss.

$\mathrm{CPB}$ was set up as previously described. ${ }^{8}$ The setup consisted of a venous reservoir, a roller pump, a hollow-fiber oxygenator (Sorin, Mirandola, Italy), and a vacuum regulator with an applied pressure of $-30 \mathrm{~mm} \mathrm{H}_{2} \mathrm{O}$ to facilitate venous drainage, all connected by $1.6-\mathrm{mm}$ internal diameter plastic tubing. Total priming volume was $10.5 \mathrm{~mL}$, gas exchange surface was $450 \mathrm{~cm}^{2}$, and heat exchange surface was $15.8 \mathrm{~cm}^{2}$.

\section{Study Design}

$\mathrm{CPB}$ was instituted at a flow rate of $120 \mathrm{~mL} \cdot \mathrm{kg}^{-1} \cdot \mathrm{min}^{-1}$. A core temperature of $15^{\circ} \mathrm{C}$ to $13^{\circ} \mathrm{C}$ was achieved over 30 minutes using CPB-assisted cooling. The roller pump was turned off and DHCA, as confirmed by asystole and lack of measurable mean arterial pressure, was maintained for 15 minutes at $13^{\circ} \mathrm{C}$ to $15^{\circ} \mathrm{C}$.

With the reinstitution of $\mathrm{CPB}$, rewarming started at a flow rate of 100 $\mathrm{mL} \cdot \mathrm{kg}^{-1} \cdot \mathrm{min}^{-1}$. At the beginning of rewarming, rats were randomly assigned to treatment with levosimendan (loading dose of $12 \mu \mathrm{g} / \mathrm{kg}$, infusion of $0.2 \mu \mathrm{g} \cdot \mathrm{kg}^{-1} \cdot \mathrm{min}^{-1}$ ) or epinephrine (loading dose of $0.1 \mu \mathrm{g} / \mathrm{kg}$, infusion of $0.1 \mu \mathrm{g} \cdot \mathrm{kg}^{-1} \cdot \mathrm{min}^{-1}$ ) or saline as control.

Infusion started at $20^{\circ} \mathrm{C}$ and was performed until CPB weaning. CPB inflow rate was gradually increased, reaching the full rate of $120 \mathrm{~mL} \cdot \mathrm{kg}^{-1} \cdot \mathrm{min}^{-1}$ at the end of rewarming at $36^{\circ} \mathrm{C}$ in a period of 60 minutes. Rewarming was assisted by a heating blanket and a heating lamp. The temperature gradient between the CPB circuit and body core did not exceed $10^{\circ} \mathrm{C}$. After full rewarming, the remaining priming volume was reinfused and animals were weaned from CPB. After the experiment, animals were humanely killed by anesthetic overdose.

\section{Measurements}

Hemodynamic parameters were collected continuously during the experiments with a 2 F Mikro-Tip pressure-volume (P-V) conductance catheter (SPR-838; Millar Instruments, Inc, Houston, Tex) inserted into the right carotid artery and advanced into the left ventricle. Signals were continuously recorded at a sampling rate of 1000 samples/s using a P-V conductance system (MPVS-400; Millar Instruments), stored, and displayed on a personal computer by the PowerLab Chart5 Software System (AD Instruments, Colorado Springs, Colo). With the use of a special P-V analysis program (PVAN; Millar Instruments), heart rate, mean arterial pressure (MAP), maximal slope of the systolic pressure increment ( $\mathrm{dP} / \mathrm{dt})$ and the diastolic pressure decrement $\left(\mathrm{dP} / \mathrm{dt}_{\text {MIN }}\right)$, and time constant of left ventricular (LV) pressure decay (Tau, according to the Weiss method) were computed and calculated. Stroke volume (SV) and cardiac output were calculated and corrected according to in vitro and in vivo volume calibrations using PVAN software. ${ }^{9}$

In addition to the above parameters, LV P-V relations were measured by transiently occluding the inferior vena cava (reducing preload) under the diaphragm by tying a snare suture around the vein at baseline condition and after $\mathrm{CPB}$ weaning. The slope of the LV end-systolic P-V relationship (ESPVR), preload recruitable stroke work, and the $\mathrm{dP} / \mathrm{dt}-\mathrm{EDV}$ relation were calculated as load-independent indexes of LV contractility. The slope of the LV end-diastolic P-V relationship (EDPVR) was calculated as reliable index of LV stiffness. ${ }^{9}$

Lactate levels were measured on arterial blood samples collected after the end of CPB-assisted rewarming.

\section{Statistical Analysis}

Results are presented as means \pm standard error. For between-group comparisons, 1-way analysis of variance was used, followed by an unpaired 2-tailed Student $t$ test or paired $t$ test to evaluate differences between groups and within groups versus the baseline, respectively.

\section{RESULTS}

Forty-five rats were used in this study and randomized into 3 groups. In the control group, 3 animals had ventricular fibrillation during rewarming and 2 had an MAP less than $40 \mathrm{~mm} \mathrm{Hg}$ after rewarming. In the epinephrinetreated group, 2 rats had ventricular fibrillation during rewarming. These animals were excluded from the data analysis. In the levosimendan-treated groups, there were no arrhythmic episodes and all 15 rats were successfully rewarmed.

There were no differences in baseline hemodynamic parameters among the 3 groups (Figure 1). During hypothermia at $20^{\circ} \mathrm{C}$, it was possible to collect hemodynamic data by temporarily turning off the roller pomp. Compared with baseline normothermia, during deep hypothermia there was a marked reduction $(60 \%-95 \%)$ in most hemodynamic parameters (Figure 1). However, SV was significantly increased $(30 \%)$ at $20^{\circ} \mathrm{C}$. Full cardiac arrest was achieved at $14^{\circ} \mathrm{C}$ in all animals.

After rewarming, MAP was significantly increased in epinephrine-treated rats compared with control and up to $20 \%$ higher than the baseline values. In the 

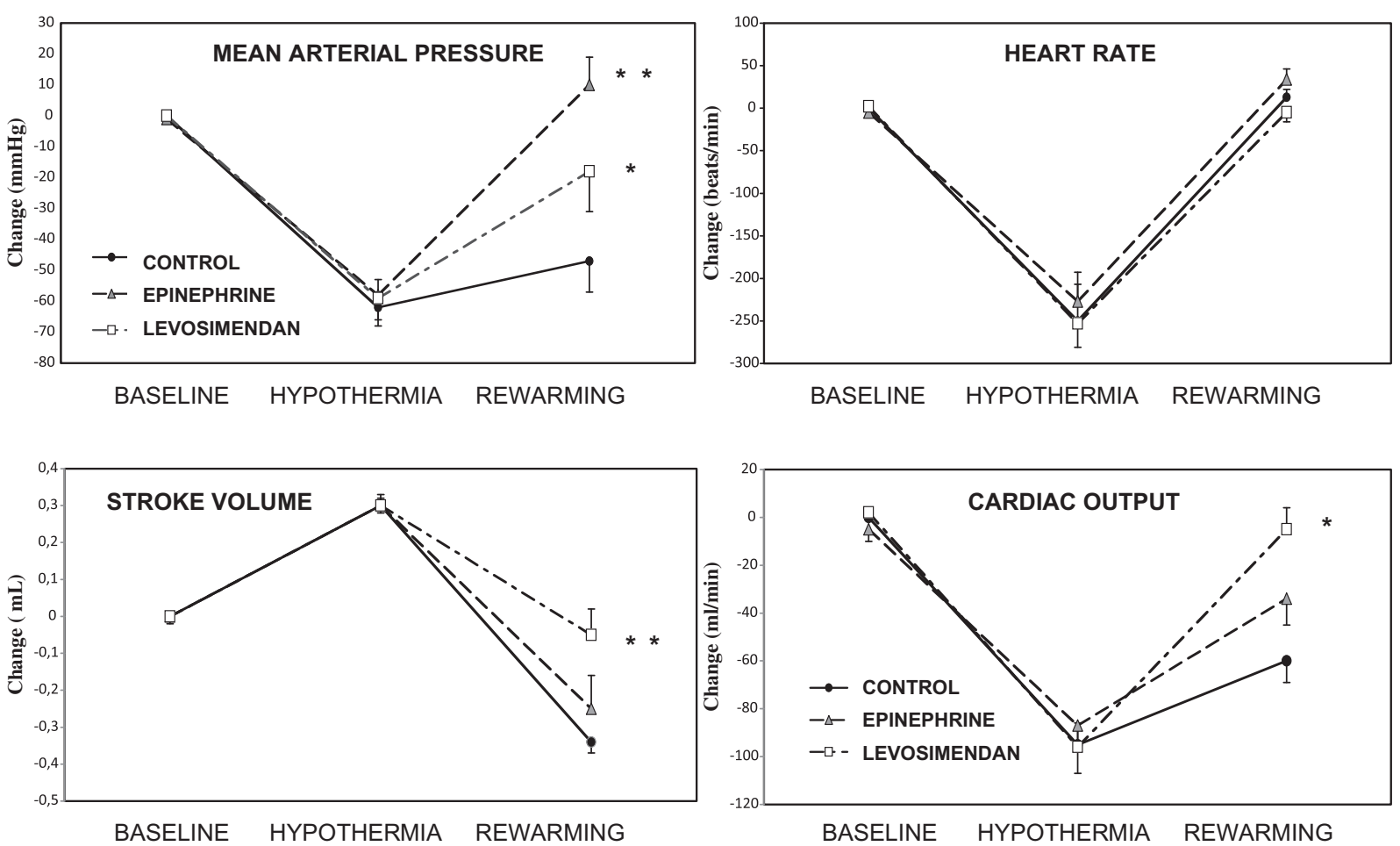

FIGURE 1. Common clinical hemodynamic parameters at baseline normothermia, during hypothermia (recorded by temporarily turning off $\mathrm{CPB}$ at $20^{\circ} \mathrm{C}$ ), and after rewarming. Values represent absolute changes (means \pm standard deviations). ${ }^{*} P<.05 ; * * P<.01$. $C P B$, Cardiopulmonary bypass.

levosimendan-treated group, MAP was significantly higher compared with control but up to $35 \%$ lower than baseline values. Heart rate completely recovered after rewarming and was similar to baseline in all 3 groups with a nonstatistically significant elevation in the epinephrine group.
After rewarming, SV was similar to baseline only in levosimendan-treated rats and was significantly higher compared with both the control and epinephrine-treated groups. In the same way cardiac output was significantly improved only in levosimendan-treated rats compared
EPINEPHRINE

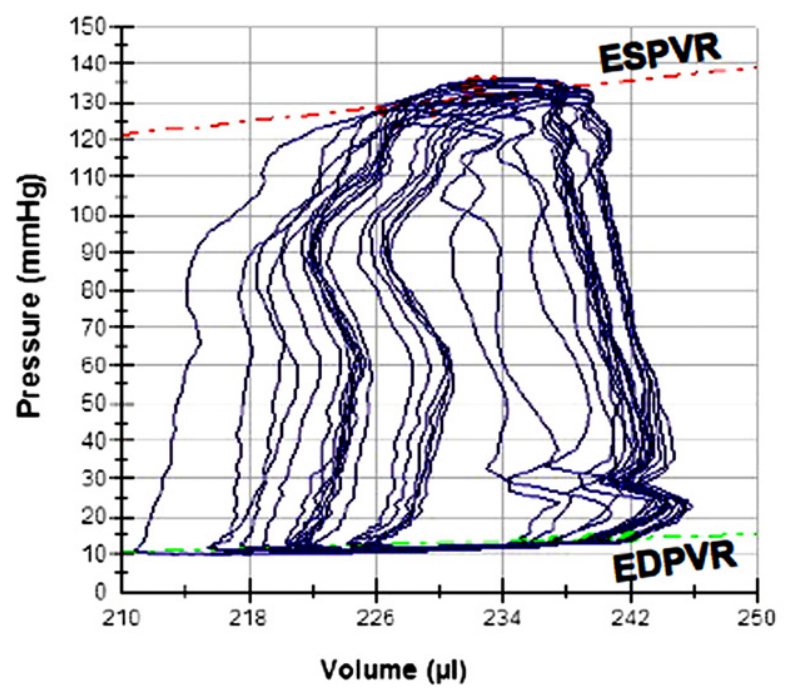

LEVOSIMENDAN

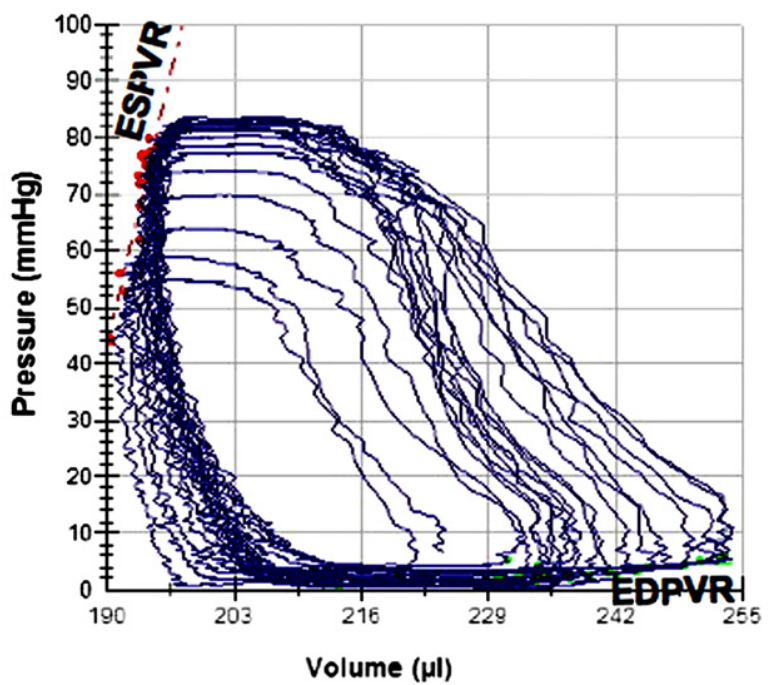

FIGURE 2. End-systolic pressure-volume $(P-V)$ relationship (ESPVR) and end-diastolic P-V relationship (EDPVR). Original recordings of representative $\mathrm{P}-\mathrm{V}$ loops were obtained with a P-V conductance catheter system at different preloads during vena cava occlusion and showed differences in ESPVR and EDPVR between epinephrine- and levosimendan-treated rats. The increased slope steepness of ESPVR and decreased of EDPVR in levosimendan indicate improved contractile function and diminished diastolic stiffness, respectively. 

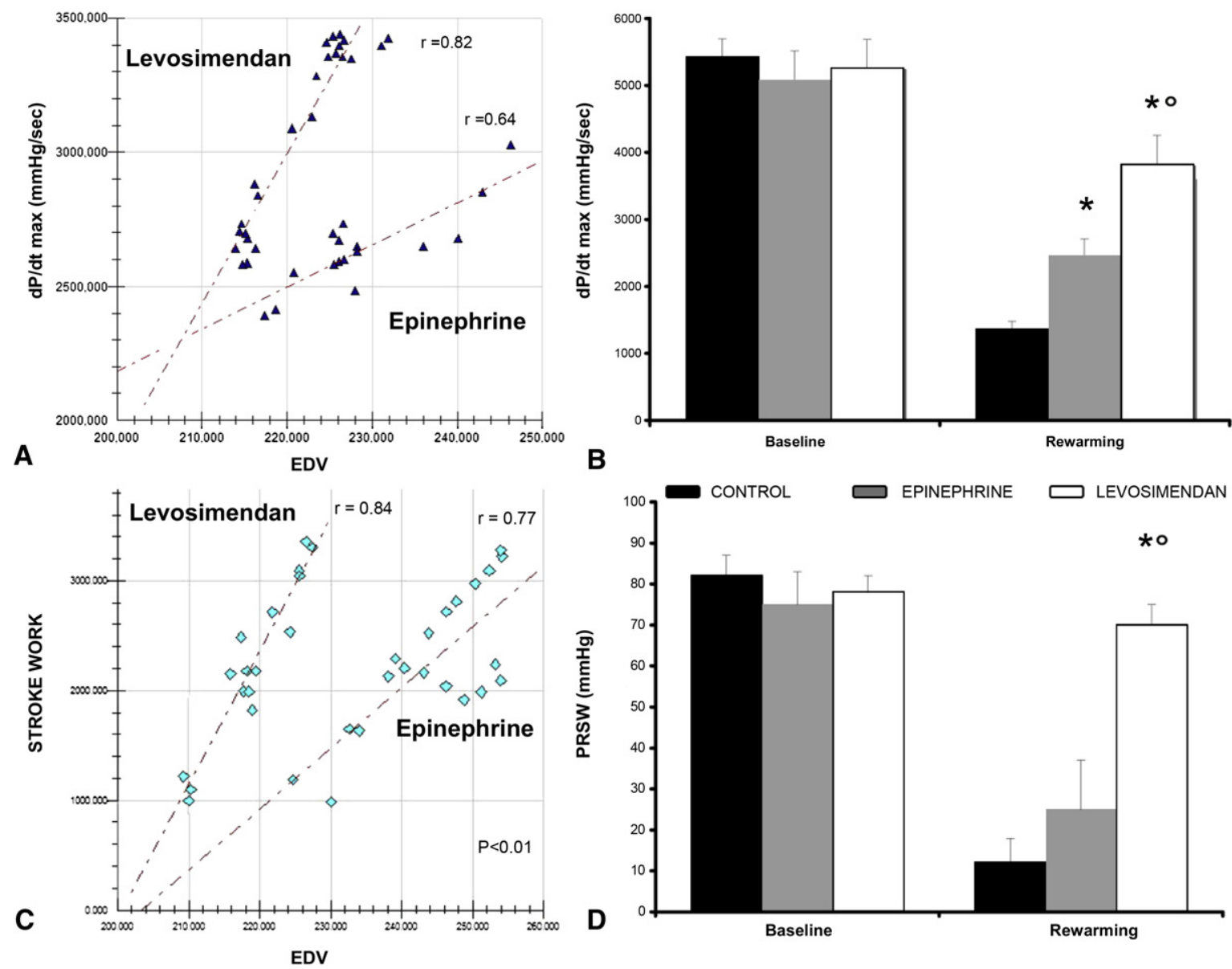

FIGURE 3. Maximal slope of the systolic pressure increment $\left(d P / d t_{\text {max }}\right)$ and end-diastolic volume $(E D V)$ relationship. The relation between $\mathrm{dP} / \mathrm{dt}_{\mathrm{MAx}}$ and EDV in 1 representative rat from the levosimendan- and epinephrine-treated groups is shown. Note that the slope values were higher in levosimendan-treated than in epinephrine-treated rats, suggesting that systolic performance is improved after levosimendan infusion (A). Maximal slope of the systolic pressure increment $\left(d P / d t_{\max }\right)$ at baseline normothermia and after hypothermia-rewarming is shown in the control group (black bar), epinephrine group (gray bar), and levosimendan group (white bar). $* P<.05$ versus control; ${ }^{\circ} P<.05$ versus epinephrine (B). C and D, Preload recruitable stroke work $(P R S W)$. The relation between stroke work and EDV in 1 representative rat from epinephrine and levosimendan group is shown. Note that slope values were higher in levosimendan rats than in epinephrine rats, suggesting that systolic performance is augmented in levosimendan (C). PRSW is the slope value of the relationship between stroke work and end-diastolic volume (EDV) in the groups of control, levosimendan, and epinephrine. ${ }^{*} P<.05$ versus control; ${ }^{\circ} P<.05$ versus epinephrine (D).

with control, although epinephrine showed a clear improvement without reaching significance.

Functional indices derived from P-V analysis at different preloads are less influenced by loading conditions. Figure 2 shows representative original P-V loops registered during transient occlusion of the inferior vena cava after rewarming in epinephrine-treated and levosimendan-treated rats. ESPVR was steeper after levosimendan infusion than after epinenephrine infusion, suggesting a better systolic performance after levosimendan infusion during rewarming. This was confirmed by $\mathrm{dP} /$ $\mathrm{dt}_{\mathrm{MAX}}$ and $\mathrm{dP} / \mathrm{dt}_{\mathrm{MAX}}$ related to EDV. $\mathrm{dP} / \mathrm{dt}_{\mathrm{MAX}}$ is a classic contractility parameter, but it is dependent on changes in preload. Analysis of the relation ofdP/dt $\mathrm{dAX}_{\mathrm{MAX}}$ to EDV allowed a comparison of $\mathrm{dP} / \mathrm{dt}_{\mathrm{MAX}}$ values of epinephrinetreated and levosimendan-treated rats at a given EDV
(Figure 3). The slope of this relation was steeper in the levosimendan-treated group. Another confirmation came from preload recruitable stroke work (the slope of the linear elation between stroke work and EDV) (Figure 3). The slope was steeper after levosimendan treatment compared with epinephrine treatment, indicating an improved systolic function determined by levosimendan in this setting. Compared with the corresponding control animals, the overall preload recruitable stroke work values were significantly improved (Figure 3).

The diastolic function after rewarming was described by $\mathrm{LV}$ relaxation index ( $\mathrm{dP} / \mathrm{dt}_{\text {MIN }}$ and Tau) and stiffness index (EDPVR) (Figure 4). Levosimendan significantly ameliorated LV relaxation compared with control. Epinephrine only improved Tau compared with control although to a lesser extent than levosimendan. The last improvement 


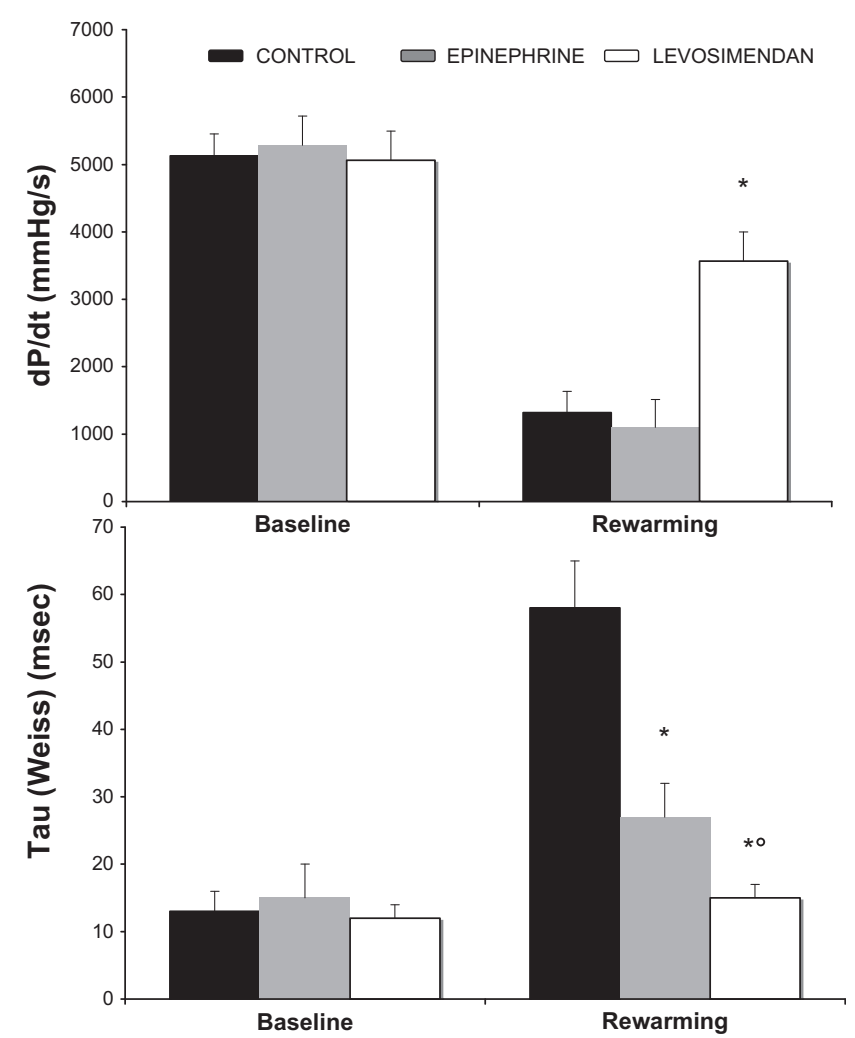

FIGURE 4. Indexes of left ventricular $(L V)$ relaxation. Maximal slope of the $\mathrm{LV}$ diastolic pressure decrement $\left(d P / d t_{\text {min }}\right)$ and time constant of LV pressure decay $(\mathrm{Tau})$ at baseline normothermia and after hypothermia-rewarming in control group (black bar), epinephrine group ( gray bar), and levosimendan group (white bar). $* P<.05$ versus control; ${ }^{\circ} P<.05$ versus epinephrine.

of EDPVR compared with epinephrine but the difference was not statistically significant.

The lactate levels were significantly higher after treatment with epinephrine and in the control group than after levosimendan infusion (Figure 5).

\section{DISCUSSION}

Whereas moderate hypothermia is a recognized method of myocardial protection in cardiac surgery, ${ }^{10,11}$ deep hypothermia, be it induced as a neuroprotective measure during aortic arch interventions or be it accidental, induces an overall myocardial depression owing to both systolic and diastolic dysfunction. ${ }^{3}$ Although often transient, more permanent injury in the form of necrosis and apoptosis might occur. Pulmonary dysfunction, which is frequently associated with hypothermia-induced myocardial dysfunction, exacerbates the low cardiac output state. ${ }^{2}$

Experimental models of deep hypothermia and rewarming confirm and explain this clinical finding. ${ }^{10,12}$ In an experimental animal model of DHCA, LV contractility, relaxation, and afterload were markedly, but transiently, depressed early after reperfusion and mildly depressed late after reperfusion. ${ }^{13}$

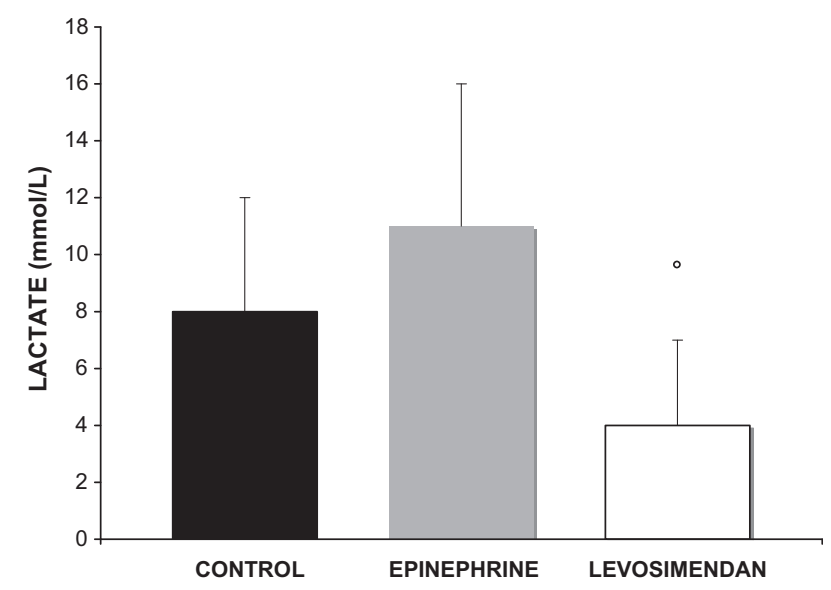

FIGURE 5. Lactate plasma levels after rewarming in the 3 groups. ${ }^{\circ} P<.05$ versus epinephrine.

The determination of the pathophysiologic mechanisms underlying cardiac dysfunction after hypothermia-rewarming attributes a pivotal role to $\mathrm{Ca}^{2+}$ overload and to the paradoxically reduced myofilament $\mathrm{Ca}^{2+}$ sensitivity. ${ }^{14}$ The phosphorylation of troponin I represents a well-established mechanism for decreased myofilament $\mathrm{Ca}^{2+}$ sensitivity. The same phosphorylation could be mediated by phosphokinase A activated by $\beta$-adrenergic stimulation. ${ }^{15}$

Moreover, cardiovascular effects mediated by $\beta$-adrenoceptors are significantly diminished after hypothermia, suggesting that the use of $\beta$-adrenoceptor-specific agonist should be reconsidered. ${ }^{16}$ Besides, pharmacologic therapy with catecholamines presents substantial limitations because these are associated with elevated myocardial oxygen consumption, arrhythmogenesis, and regional hypoperfusion leading to organ damage. ${ }^{17,18}$

Levosimendan is a pyridazinone dinitrite derivative belonging to the new inotropic drugs class of $\mathrm{Ca}^{2+}$ sensitizer. It presents a positive inotropic effect by sensitizing cardiac troponin $\mathrm{C}$ to calcium during systole, thus increasing cardiac performance without increasing myocardial oxygen consumption and with a weak arrythmogenic effect. ${ }^{18}$

To the best of our knowledge, no data have been published about the efficacy of levosimendan in improving myocardial dysfunction after deep hypothermia-rewarming.

This study was conducted on a rat model of CPB previously validated and described. ${ }^{8}$ DHCA and CPB-assisted rewarming reproduced the clinical setting of both cardiac surgery interventions and extracorporeal resuscitation after accidental hypothermia. The results of this study demonstrated that levosimendan treatment during rewarming produced a significant improvement of clinical used parameters of cardiac functions (heart rate, MAP, SV, and cardiac output). In the same manner, more precise parameters derived from P-V analysis and insensitive to preload effect confirmed significantly improved systolic function after levosimendan treatment when compared with epinephrine. 
Epinephrine produced an increased MAP without an improvement in SV and an important elevation in lactate levels, which were significant higher than levosimendan. Moreover, levosimendan was superior in improving diastolic function, which was evident on LV relaxation indexes.

Further investigations are needed to validate these results in the clinical setting and to evaluate the cost/benefit ratio in high-risk patients. Nonetheless, on the basis of these findings, use of $\mathrm{Ca}^{2+}$ sensitizer drugs, such as levosimendan, seems rational in induced or accidental deep hypothermia.

The clinical experience with levosimendan is limited to weaning from conventional CPB. Its superiority over catecholamines was already demonstrated as postoperative rescue therapy for high-risk patients difficult to wean from CPB. ${ }^{18-20}$ The hemodynamic data were limited on systolic function and were consistent with results of this study. However, no data exist about effect of levosimendan on diastolic function after CPB.

Finally, some important limitations remain. The animal model does not faithfully reproduce the clinical setting. In addition, inasmuch as only a single dose of epinephrine and levosimendan with a particular treatment regimen (single loading dose at the beginning of rewarming and then continuous infusion from $20^{\circ} \mathrm{C}$ to complete rewarming) was investigated, one cannot rule out the possibility that different dosages or treatment schemes might have generated different functional outcomes from the one herein. Nevertheless, this particular treatment regimen for ephinephrine was deliberately chosen to compare results with prior studies. $^{4-6}$

\section{CONCLUSIONS}

Levosimendan has better inotropic and lusitropic effects than epinephrine during rewarming from experimental DHCA.

\section{References}

1. Jonas RA. Hypothermia, circulatory arrest, and the pediatric brain. J Cardiothorac Vasc Anesth. 1996;10:66-74.

2. Duffy JY, McLean KM, Lyons JM, Czaikowski AJ, Wagner CJ, Pearl JM. Modulation of nuclear factor-kappaB improves cardiac dysfunction associated with cardiopulmonary bypass and deep hypothermic circulatory arrest. Crit Care Med. 2009;37:577-83.

3. Vassal T, Benoit-Gonin B, Carrat F, Guidet B, Maury E, Offenstadt G. Severe accidental hypothermia treated in an ICU: prognosis and outcome. Chest. 2001; 120:1998-2003.

4. Kondratiev TV, Myhre ES, Simonsen O, Nymark TB, Tveita T. Cardiovascular effects of epinephrine during rewarming from hypothermia in an intact animal model. J Appl Physiol. 2006;100:457-64.

5. Peberdy MA, Callaway CW, Neumar RW, Geocadin RG, Zimmerman JL, Donnino M, et al. Part 9: post-cardiac arrest care: 2010 American Heart Association Guidelines for Cardiopulmonary Resuscitation and Emergency Cardiovascular Care. Circulation. 2010;122(18 Suppl. 3):S768-86.

6. Sun S, Tang W, Song F, Yu T, Ristagno G, Shan Y, et al. The effects of epinephrine on outcomes of normothermic and therapeutic hypothermic cardiopulmonary resuscitation. Crit Care Med. 2010;38:2175-80.

7. Deakin CD, Nolan JP, Soar J, Sunde K, Koster RW, Smith GB, et al. European Resuscitation Council Guidelines for Resuscitation 2010 Section 4. Adult advanced life support. Resuscitation. 2010;81:1305-52.
8. Cresce GD, Walpoth BH, Mugnai D, Innocente F, Rungatscher A, Luciani GB, et al. Validation of a rat model of cardiopulmonary bypass with a new miniaturized hollow fiber oxygenator. ASAIO J. 2008;54:514-8.

9. Pacher P, Nagayama T, Mukhopadhyay P, Batkai S, Kass DA. Measurement of cardiac function using pressure-volume conductance catheter technique in mice and rats. Nat Protoc. 2008;3:1422-34.

10. Filseth OM, How OJ, Kondratiev T, Gamst TM, Tveita T. Post-hypothermic cardiac left ventricular systolic dysfunction after rewarming in an intact pig model. Crit Care. 2010;14:R211.

11. Götberg M, van der Pals J, Olivecrona GK, Götberg M, Koul S, Erlinge D. Mild hypothermia reduces acute mortality and improves hemodynamic outcome in a cardiogenic shock pig model. Resuscitation. 2010;81:1190-6.

12. Kondratiev TV, Wold RM, Aasum E, Tveita T. Myocardial mechanical dysfunction and calcium overload following rewarming from experimental hypothermia in vivo. Cryobiology. 2008;56:15-21.

13. Velvis H, Hines MH, Klopfenstein HS, Berry DD, Vinten-Johansen J. Depression of cardiac function after deep hypothermic circulatory arrest in deeply anesthetized neonatal lambs. J Thorac Cardiovasc Surg. 1996;111:359-66.

14. Han YS, Tveita T, Prakash YS, Sieck GC. Mechanisms underlying hypothermiainduced cardiac contractile dysfunction. Am J Physiol Heart Circ Physiol. 2010; 298:H890-7.

15. Layland J, Solaro RJ, Shah AM. Regulation of cardiac contractile function by troponin I phosphorylation. Cardiovasc Res. 2005;66:12-21.

16. Han YS, Tveita T, Kondratiev TV, Prakash YS, Sieck GC. Changes in cardiovascular beta-adrenoceptor responses during hypothermia. Cryobiology. 2008;57:246-50.

17. Lochner A, Colesky F, Genade S. Effect of a calcium-sensitizing agent, levosimendan, on the postcardioplegic inotropic response of the myocardium. Cardiovasc Drugs Ther. 2000;14:271-81.

18. Siirilä-Waris K, Suojaranta-Ylinen R, Harjola VP. Levosimendan in cardiac surgery. J Cardiothorac Vasc Anesth. 2005;19:345-9.

19. Akgul A, Mavioglu L, Katircioglu SF, Pac M, Cobanoglu A. Levosimendan for weaning from cardiopulmonary bypass after coronary artery bypass grafting. Heart Lung Circ. 2006;15:320-4. Epub 2006 Jul 24.

20. Eriksson HI, Jalonen JR, Heikkinen LO, Kivikko M, Laine M, Leino KA, et al. Levosimendan facilitates weaning from cardiopulmonary bypass in patients undergoing coronary artery bypass grafting with impaired left ventricular function. Ann Thorac Surg. 2009;87:448-54.

\section{Discussion}

Dr Paul M. Kirshbom (Atlanta, $G a$ ). No disclosures. I have just a couple of quick questions. I could not tell from your presentation whether the animals were off bypass when you did your hemodynamic studies at the end or whether they were still on bypass.

Dr Rungatscher. They went through a complete cardiopulmonary-assisted rewarming, until they reached $36^{\circ} \mathrm{C}$, then bypass was weaned and they subsequently underwent hemodynamic analysis by vena cava occlusion method.

Dr Kirshbom. So they were off bypass.

Just 1 quick question. Why do you think the lactate was increased given the fact they were on bypass for the entire study and they were off for a very brief period? Obviously, they were on full bypass. Why would the lactate be increased for that very brief period?

Dr Rungatscher. The arterial lactate levels were increased as a result of 15 minutes of deep hypothermic circulatory arrest followed by cardiopulmonary bypass-assisted reperfusion. Results indicated that reperfusion with levosimendan administration produced a better clearance of lactate than both epinephrine and control. Moreover, lactate after epinephrine infusion was even higher than control, suggesting a noncomplete reperfusion of some region of the body because of the vasoconstrictive effect of epinephrine.

Dr Kirshbom. So your pump flows were comparable between groups?

Dr Rungatscher. Yes. 